Int. J. Electrochem. Sci., 16 (2021) Article ID: 210556

International Journal of

ELECTROCHEMICAL

SCIENCE

WWW.electrochemsci.org

\title{
Electrochemical Determination of Ascorbic Acid, Dopamine and Uric Acid at Polyaniline-Graphene Nanocomposites Modified Electrode
}

\author{
Ling Shi, Na Wu, Wei Liu, Guangming Yang, Zefeng Wang* \\ School of science, Honghe University, mengzi, Yunnan 661199, PR China \\ *E-mail: wangzefeng841006@163.com
}

doi: $10.20964 / 2021.05 .27$

Received: 18 January 2021 / Accepted: 5 March 2021 / Published: 31 March 2021

In this work, we proposed a novel liquid-liquid interface polymerization method for preparing of PANI/GN nanocomposites. The interface polymerization method can effectively suppress secondary growth. This method was benefit for growing PANI onto GN surface uniformly. Then an electrochemical sensor for the determination of DA, AA, and UA was fabricated on glassy carbon electrode (GCE) modified with the obtained PANI/GN nanocomposites. Cyclic voltammetry (CV) and amperometric i-t curve were performed to investigate the electrochemical behaviour of DA, AA, and UA. The results indicated the PANI/GN-modified electrode had a good electrochemical response toward $\mathrm{AA}, \mathrm{AD}$, and $\mathrm{UA}$ in the concentrations range between $0.167 \mu \mathrm{M}$ to $600 \mu \mathrm{M}, 0.0557 \mu \mathrm{M}$ to 530 $\mu \mathrm{M}, 1.500 \mu \mathrm{M}$ to $890 \mu \mathrm{M}$, respectively. And the corresponding detection limit for AA, DA, and UA were $0.053 \mu \mathrm{M}, 0.019 \mu \mathrm{M}$, and $0.57 \mu \mathrm{M}$, respectively. Good detection limit of $0.053 \mu \mathrm{M}, 0.019 \mu \mathrm{M}$, and $0.57 \mu \mathrm{M}$ were achieved for determination of $\mathrm{AA}, \mathrm{AD}$, and $\mathrm{UA}$, respectively.

Keywords: graphene; polyaniline; electrochemical sensor; ascorbic acid; dopamine; uric acid

\section{$\underline{\text { FULL TEXT }}$}

(C) 2021 The Authors. Published by ESG (www.electrochemsci.org). This article is an open access article distributed under the terms and conditions of the Creative Commons Attribution license (http://creativecommons.org/licenses/by/4.0/). 